\title{
Evaluation of acute flaccid paralysis surveillance system in Kerkuk governorate
}

\author{
Dr. Zaid M. Yassen
}

Department of Community Medicine, Mosul College of Medicine, University of Mosul

(Ann. Coll. Med. Mosul 2007; 33(1\&2):59-65)

Received: $2^{\text {nd }}$ Sept 2007; accepted $2^{\text {nd }}$ Jan. 2008.

\section{ABSTRACT:}

Context: High quality acute flaccid paralysis surveillance system is a aquite important strategy for polio eradication. Surveillance data are the cornerstone to document a national polio free status. The aim of the present study is to evaluate the acute flaccid paralysis surveillance system in Kerkuk Governorate.

Methods: Program evaluation of the Directorate of health, primary health care districts (sectors), hospitals, and primary health care centers in Kerkuk Governorate. All the responsible personnel for the acute flaccid paralysis surveillance system were interviewed and included in addition to the relevant records. Ordinary percentages were used in the description of acute flaccid paralysis cases. While rates were used in the evaluation of the performance indicators.

Results: The study revealed a sensitive acute flaccid paralysis surveillance system (Non polio acute flaccid paralysis rate 3.98 and 3.1 in 2005 and 2006 respectively) with clear field guidelines. All the performance indicators were high indicating a high quality surveillance system in Kerkuk Governorate.

Conclusions: Solid surveillance structure, regular contract and excellent case management were observed, in addition to regular passive and active surveillance.

$$
\begin{aligned}
& \text { الخلاصة: } \\
& \text { الهدف: تهدف الدر اسة الحالية إلى تقييم برنامج الرصد الوبة الوبائي للشلل الرخوي الحاد في محافظة كركوك . }
\end{aligned}
$$

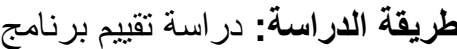

$$
\begin{aligned}
& \text { مكان الدراسة : أجريت الدر اسة في دائرة صحة كركوك إضافة إلى قطاعات الر عاية الصحية الأوليـة والمستشفيات }
\end{aligned}
$$

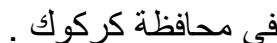

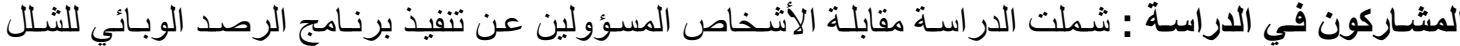

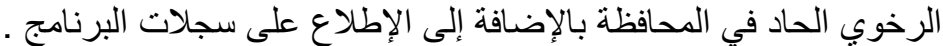

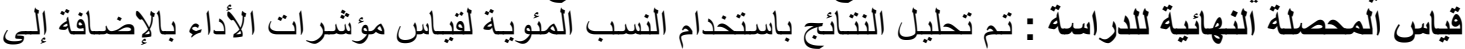

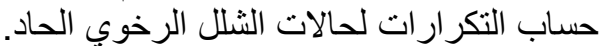

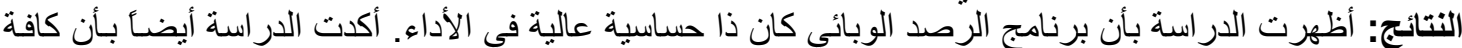

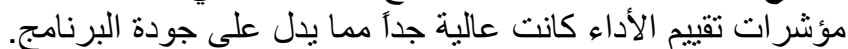

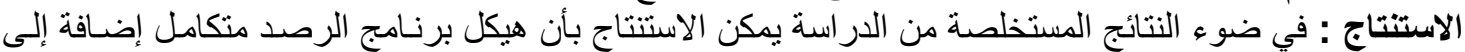

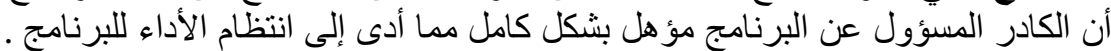


$\mathrm{P}$ oliomyelitis is a highly contagious disease caused by poliovirus. High fraction (about 95\%) of all polio infections are inapparent or subclinical; only $2 \%$ result in acute flaccid paralysis (AFP) $(1,3)$

Acute flaccid paralysis is a complex clinical syndrome with a broad array of potential etiologies including paralytic polio, Guillian Barre syndrome, transverse myelitis, traumatic neuritis, meningitis, encephalitis, and brain tumours ${ }^{(2,4)}$.

In 1988, the world health assembly adopted a resolution calling for global eradication of poliomyelitis by the year $2000^{(5)}$. Iraq has made significant progress in polio eradication, National activities started since 1995, by conducting a series of activities including increase in oral polio vaccine (OPV) routine coverage and strengthening AFP surveillance system ${ }^{(6)}$. The last indigenous wild poliovirus was isolated in Iraq in January $2000^{(7)}$.

All endemic and many non-endemic countries including Iraq implement both intense programs of supplementary immunization campaigns and continue to improve AFP surveillance systems ${ }^{(8)}$. Surveillance is the collection, analysis, interpretation, and dissemination of information about a selected health event $^{(9,12)}$.

As more countries become polio free the ability to prove the absence of circulating virus or to identify importation of poliovirus into free areas become increasingly crucial for national eradication programs; this makes high quality surveillance is quite important for both endemic and polio free countries $^{(8)}$.

Data generated by high quality, reliable AFP surveillance system form the cornerstone to formally document national polio free status ${ }^{(8)}$.

Acute flaccid paralysis surveillance performance indicators in Iraq suffered immediately after the war but a lot of efforts were conducted by the national staff with the support of the World Health Organization (WHO) which were quite successful ${ }^{(6-9)}$.

Acute flaccid paralysis surveillance is considered as an essential strategy in polio eradication. It has many important roles which are: identifying high risk areas or groups, monitoring the progress of eradication programs, certifying a country polio free, and utilizing data to chose supplementary activities ${ }^{(9,10)}$.

The aim of the present study is to evaluate the quality of the AFP surveillance system in Kerkuk Governorate through calculating the performance indicators and comparing it with the international targets.

\section{Material and Methods:}

The present study is a part of a national program of AFP surveillance evaluation; it is conducted after approval of the Ministry of Health $(\mathrm{MOH})$ and the support of the WHO during the period from $10^{\text {th }}$ of Dec. 2006 to the $29^{\text {th }}$ of Jan. 2007.

The investigator participated in a training workshop on the national and international guidelines of AFP surveillance evaluation and its performance indicators before the initiation of the present study. Moreover the investigator has been chosen by the $\mathrm{MOH}$ to conduct the evaluation in Kerkuk Governorate.

The investigator paid a visit to the Directorate of Health (DOH) in Kerkuk Governorate to conduct a primary meeting with the director general, the main objectives of the study were explained and the administrative approval of the director general was obtained.

The evaluation process was conducted at three levels, regional (DOH), intermediate i.e. Districts (sectors), and local level (primary health care centers (PHCCs) and hospitals).

Field visits were conducted to the department of primary health care (PHC), in addition to all the AFP surveillance focal points in the PHC districts and hospitals. On the other hand 12 PHCCs in the governorates were visited centers. Those which are located in areas with bad security circumstances were excluded. Figure (1) shows the levels of evaluation of the present work.

Focal points personnel, active surveillance personnel, PHC district and PHC center managers were interviewed in addition to 
specialist pediatricians, community medicine specialists, general practitioners, medical and laboratory technicians to evaluate their knowledge about the surveillance system according to the WHO field guidelines ${ }^{(7)}$.

Furthermore, all the relevant records of the active and passive surveillance were observed and evaluated, the AFP cases data were recorded using a special form prepared by the investigator based on the $\mathrm{WHO}$ protocol of the assessment of national AFP surveillance system ${ }^{(10)}$. All the performance indicators were calculated and compared to the international targets; these indicators were adopted by the $\mathrm{WHO}$ and calculated as follows(10):

.Non polio AFP Rate in children < 15 years $=$ No. of reported Non polio AFP cases $<15$ / total No of children $<15 * 100000$ .Completeness of weekly and monthly reporting $=$ No of reports received $/$ No of reports expected ${ }^{*} 100$.

.Timeliness of weekly and monthly reporting $=$ No of reports received before a specified deadline/ No of reports expected *100.

.Reported AFP cases with 2 stool specimens collected in $\leq 14$ days since onset $=$ No of AFP cases with 2 stool specimens collected in $\leq 14$ days since onset / total AFP cases reported *100.

.Reported AFP cases with 60 days follow up to verify residual paralysis $=$ No of AFP cases with 60 days follow up / total AFP cases reported *100.

.Reported AFP cases investigated $\leq \mathbf{4 8}$ hours of report $=$ No of AFP cases investigated $\leq 48$ hours of report / total AFP cases reported * 100 .
.Specimens arriving at national lab. $\leq 3$ days of being sent $=$ No of Specimens arriving at national lab. $\leq 3$ days / total AFP cases reported *100.

.Specimens arriving national lab. in good condition $=$ No of Specimens arriving national lab. in good condition / total No of specimens arriving national lab. ${ }^{\star} 100$.

.Specimens with turnaround time $\leq \mathbf{2 8}$ days (Reporting result from lab.) $=$ No. of specimens with lab. Result within 28 days/ total No. of specimens arrived the lab. ${ }^{*} 100$. Stool Specimens from which non polio enterovirus was isolated $=$ No. of Specimens from which non polio enterovirus was isolated / total No. of specimens arrived the lab. *100

Regarding data management ordinary percentages were used in the description of acute flaccid paralysis cases. While rates were used in the evaluation of the performance indicators.

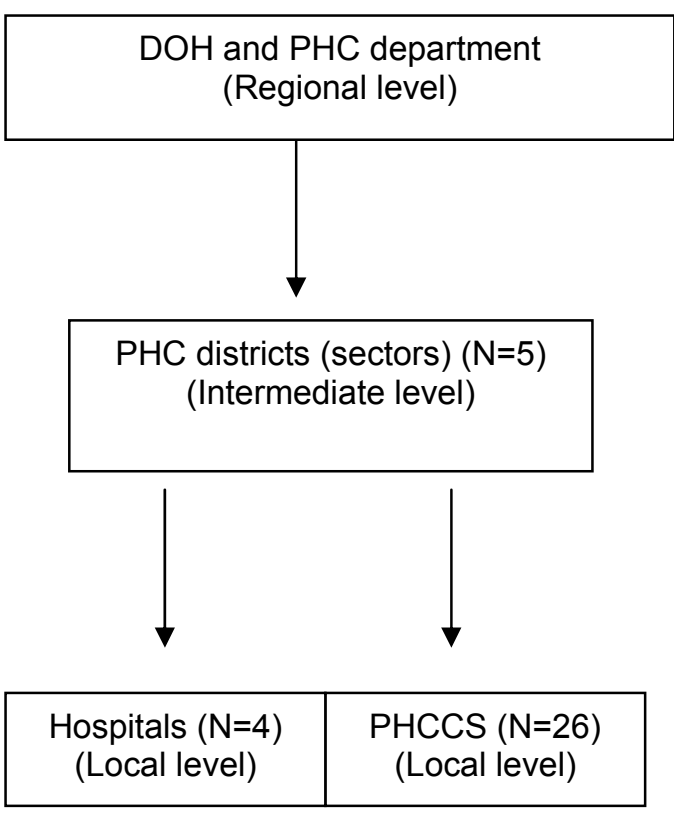

Figure (1) Levels of evaluation of AFP surveillance system in the present study. 


\section{Results:}

A total of 47 medical and health personnel were interviewed, including 4PHC districts managers, 4 hospitals managers, 12 PHCCs managers, 10 physicians, 9 AFP focal point personnel, and 8 laboratory technicians.

Table (1) reveals that there is specific AFP surveillance structure; it is evident that more than $60 \%$ of the settings were surveyed through 39 visits. AFP surveillance focal points are present in the $\mathrm{DOH}$, districts, and hospitals. Clear field guidelines, complete documentation, regular supervisory activities, and regular contact and information exchange between different levels at the $\mathrm{DOH}$ were observed during the investigator's visits.

Table (2) shows the age and sex distribution of the AFP cases detected during 2 years period (2005 and 2006) in Kerkuk Governorate.

The table reveals that about $52 \%$ and $46 \%$ of AFP cases were males in 2005 and
2006 respectively. Around three quarters of AFP cases were $1-5$ years of age $(81.1 \%$ and $69 \%$ in 2005 and 2006 respectively); nevertheless no cases below one year of age were recorded

It is evident from Figure (2) that most frequently encountered final diagnosis for AFP was Guillian Barre syndrome which constituted $51 \%$ of the reported cases followed by traumatic neuritis, meningitis and encephalitis which constituted $3.1 \%$, $6.9 \%$, and $6.9 \%$ respectively.

Table (3) shows performance indicators for AFP surveillance system. It is evident that all indicators during 2005 and 2006 were above the target level which indicates a high quality surveillance system. The Table shows that the non polio AFP rates in children $<15$ years of age were acceptable (3.98 and 3.1 for 2005 and 2006 respectively). On the other hand more than $90 \%$ of cases were investigated within 48 hours of report and 2 stool specimens collected <14 days since onset in 2005 and 2006.

Table (1) Structure of AFP surveillance system with setting surveyed, Kerkuk Governorate 2006.

\begin{tabular}{|c|c|cc|}
\hline $\begin{array}{c}\text { Structure of surveillance } \\
\text { system by health care level }\end{array}$ & $\begin{array}{c}\text { Total No. of facilities involved } \\
\text { in AFP surveillance }\end{array}$ & \multicolumn{2}{|c|}{$\begin{array}{c}\text { No. and percent of facilities } \\
\text { surveyed } \\
\text { No. }\end{array}$} \\
\hline $\begin{array}{c}\text { Regional level } \\
\text { DOH }\end{array}$ & 1 & 1 & 100 \\
PHC department & 1 & 1 & 100 \\
\hline$\frac{\text { Intermediate level }}{\text { Districts(sectors) }}$ & 5 & 4 & 80 \\
\hline $\begin{array}{c}\text { Local level } \\
\text { PHC centers } \\
\text { Hospitals }\end{array}$ & 26 & 12 & 46 \\
\hline Total facilities available & 4 & 4 & 100 \\
\hline
\end{tabular}

Table (2) Age and sex distribution of reported AFP cases. Kerkuk Governorate 2005, 2006

\begin{tabular}{|c|c|c|c|c|c|c|}
\hline \multirow[b]{2}{*}{$\begin{array}{l}\text { Age } \\
\text { (year) }\end{array}$} & \multicolumn{3}{|l|}{2005} & \multicolumn{3}{|l|}{2006} \\
\hline & $\begin{array}{l}\text { Male } \\
\text { No. \% }\end{array}$ & $\begin{array}{c}\text { Female } \\
\text { No. } \%\end{array}$ & $\begin{array}{l}\text { Total } \\
\text { No. } \%\end{array}$ & $\begin{array}{l}\text { Male } \\
\text { No. \% }\end{array}$ & $\begin{array}{c}\text { Female } \\
\text { No. } \%\end{array}$ & $\begin{array}{l}\text { Total } \\
\text { No. } \%\end{array}$ \\
\hline $1-5$ & $9(56.1)$ & $4(25)$ & $13(81.1)$ & $4(30.2)$ & $5(38.4)$ & $9(69)$ \\
\hline $5-10$ & $1(6.3)$ & $1(6.3)$ & $2(12.6)$ & $1(8)$ & $2(15.4)$ & $3(23)$ \\
\hline $10-15$ & $0(0)$ & $1(6.3)$ & $1(6.3)$ & $1(8)$ & $0(0)$ & $1(8)$ \\
\hline Total & $10(52.4)$ & $6(37.6)$ & $16(100)$ & $6(46.2)$ & $7(53.8)$ & $13(100)$ \\
\hline
\end{tabular}


Figure (2) Final diagnosis of AFP reported cases, Kerkuk Governorate 2005, 2006

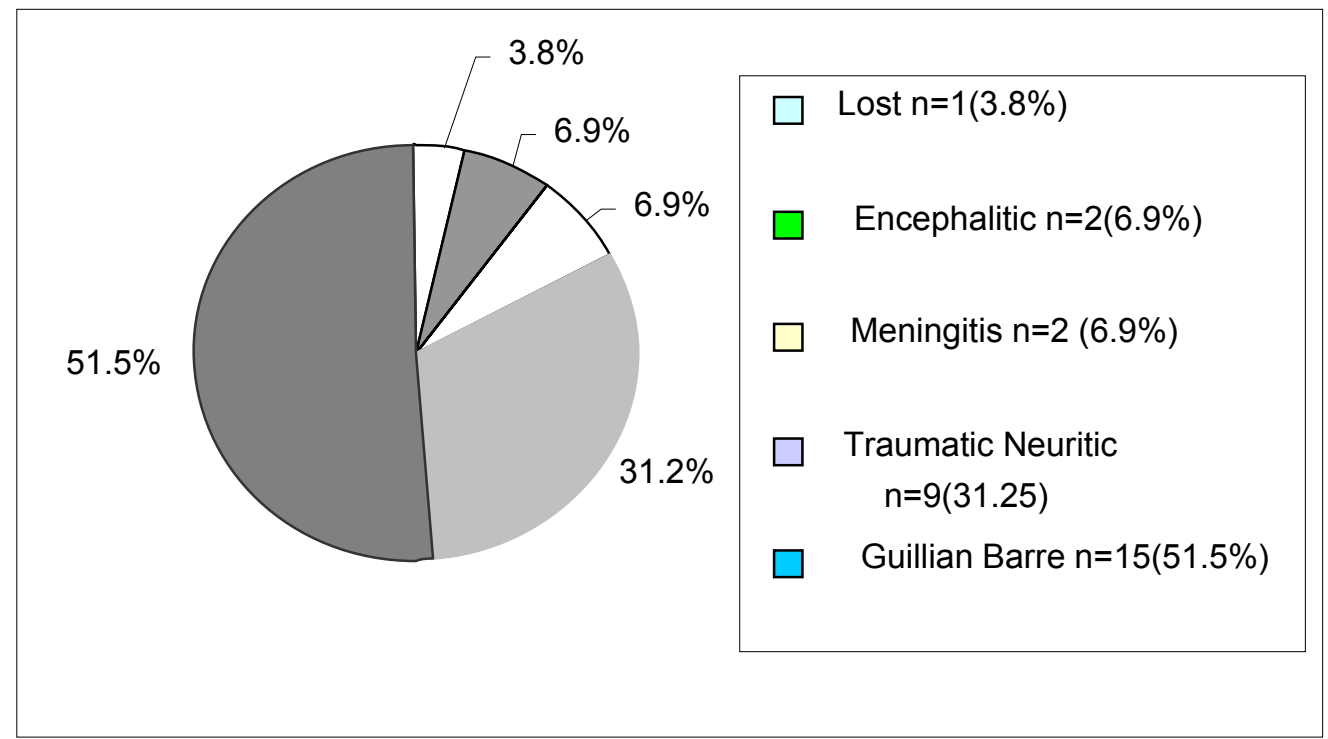

Table (3) Performance indicators for AFP surveillance system. Kerkuk Governorate 2005, 2006

\begin{tabular}{|l|c|c|c|}
\hline performance indicator & International Target Rate & Actual Rate 2005 & Actual Rate 2006 \\
\hline $\begin{array}{l}\text { Non polio AFP Rate in } \\
\text { children <15 years }\end{array}$ & $2 / 100000$ & 3.98 & 3.1 \\
\hline $\begin{array}{l}\text { Completeness of weekly and } \\
\text { monthly reporting }\end{array}$ & $\geq 90 \%$ & $96 \%$ & $100 \%$ \\
\hline $\begin{array}{l}\text { Timeliness of weekly and } \\
\text { monthly reporting }\end{array}$ & $\geq 80 \%$ & $96 \%$ & $95 \%$ \\
\hline $\begin{array}{l}\text { Reported AFP cases } \\
\text { investigated 48 hours of } \\
\text { report }\end{array}$ & $\geq 80 \%$ & $93.8 \%$ & $100 \%$ \\
\hline $\begin{array}{l}\text { Reported AFP cases with 2 } \\
\text { stool specimens collected in } \\
\leq 14 \text { days since onset }\end{array}$ & $\geq 80 \%$ & $100 \%$ & $92.3 \%$ \\
\hline $\begin{array}{l}\text { Reported AFP cases with } 60 \\
\text { days follow up to verify } \\
\text { residual paralysis }\end{array}$ & $\geq 90 \%$ & $100 \%$ & $92.3 \%$ \\
\hline $\begin{array}{l}\text { Specimens arriving at } \\
\text { national lab. } \leq \text { days of } \\
\text { being sent }\end{array}$ & $>80 \%$ & $100 \%$ & $10 \% \%$ \\
\hline $\begin{array}{l}\text { Specimens arriving national } \\
\text { lab. in good condition }\end{array}$ & $\geq 80 \%$ & $100 \%$ & $100 \%$ \\
\hline $\begin{array}{l}\text { Specimens with turnaround } \\
\text { time 28 days (Reporting } \\
\text { result from lab.) }\end{array}$ & $\begin{array}{l}\text { Stool Specimens from which } \\
\text { non entio enterovirus was } \\
\text { isolated }\end{array}$ & $100 \%$ & $93 \%$ \\
\hline
\end{tabular}




\section{Discussion:}

Health officials use the information obtained by the surveillance system to plan, implement, and evaluate health programs and activities ${ }^{(10-12)}$.

In Iraq surveillance for suspected polio were established in 1989 where only suspected polio cases were investigated; AFP surveillance was introduced in 1996 in order to look for wild polio virus circulation in the community through clinical, epidemiological, and laboratory investigations. Nevertheless, active AFP surveillance was established in $1999^{(9)}$.

For the time being AFP surveillance system is implemented in Iraq at two levels. The first is the routine zero reporting including the immediate notification of AFP cases. The second is the active surveillance, which is a strategy to actively collect information by visiting health facilities weekly (7-10)

The present study shows that the structure of the AFP surveillance in Kerkuk Governorate was solid with clear field guidelines; a similar result was obtained in another study conducted in Mosul in 2005 which shows a well established surveillance system with clear field guidelines and well trained staff ${ }^{(13)}$.

On the other hand, the level of awareness among both clinicians who are working in hospitals and PHC staff was excellent, a satisfactory relationship was observed between both levels due to the frequent joint training workshops which were conducted by the $\mathrm{DOH}$. Another study which was conducted in Mosul in 2005 showed that the $\mathrm{DOH}$ conduct a periodic training workshops in order to increase the awareness among medical staff ${ }^{(13) .}$

Regarding the age distribution of AFP cases in Kerkuk Governorate, most of the cases observed were in 1-5 years of age, nearly similar results were also demonstrated in Iraq in 2003 and 2004 by WHO survey where more than half of AFP cases were within the same age group ${ }^{(7)}$.

In the present study all the calculated performance indicators, were excellent; all were above the international target level.
Non polio AFP rates observed in 2005 and 2006 are higher than the national levels observed in 2005 and 2006 which were 2.78 and 3.04 respectively ${ }^{(6-10)}$. This result indicates a high awareness of the medical staff toward the importance of reporting every AFP case, and such high rates will increase the sensitivity of the surveillance system $^{(10) .}$

Moreover, the reported AFP cases investigated within 48 hours for 2005 and 2006 were higher than the national figures which were $82 \%$ and $81 \%$ respectively ${ }^{(6-10)}$. The same was for adequacy of stool specimen collection and specimens sent to lab within 72 hours ${ }^{(6-10)}$. This result indicates a good system performance and high staff awareness .No similar study was performed in Kerkuk governorate before this time so that one can compare the performance.

\section{Conclusions and Recommendations:}

From the results of the present study the following conclusions can be stated:

1. There is specific solid AFP surveillance system, well trained staff and clear field guidelines.

2. Regular contact, information exchange and feedback.

3. Acute flaccid paralysis case management (reporting, investigation, and 60 days follow up) are implemented in right manner.

4. Stool specimen collection implemented according to the $\mathrm{WHO}$ guidelines.

\section{The followings are recommended:}

1. Additional staff training is needed to update their knowledge

2. Additional logistic support is needed to the focal points.

3. Conducting another evaluation study in the future.

\section{References:}

1. David L. H. Control of communicable diseases manual, $18^{\text {th }}$ ed., Washington DC; American public health Assoc. 2004; 425-32.

2. Richard E., Robert M. Nelson essentials of pediatrics. $3^{\text {rd }}$ ed. Philadelphia, Saunders, 1998; 383-85. 
3. Arthur M., Jonathan D., Roland W. Differential diagnosis of acute flaccid paralysis and its role in poliomyelitis surveillance. Epidemiol Rev. 2000; 22 (2).

4. Growdon JH, Fink JS. Paralysis and movement disorder. In: Isselbacher KJ, Braunwald E, Wilson JD, eds. Harison's principles of internal medicine. New York, Mc Graw-Hill, 1994: 115-25.

5. World Health Assembly. Global eradication of poliomyelitis by the year 2000. Geneva, Switzerland: world health organization, 1988. (WHA resolution no. WHA 41.28).

6. World Health Organization. Review of acute flaccid paralysis (AFP) surveillance in Iraq. Geneva, Switzerland: WHO, 2004.

7. World Health Organization. Review of acute flaccid paralysis (AFP) surveillance in Iraq. Final report. Geneva, Switzerland: WHO, 2007.
8. World Health Organization. Review of acute flaccid paralysis (AFP) surveillance in Iraq. Geneva, Switzerland: WHO, 2004.

9. World Health Organization, Ministry of health in Iraq. Poliomyelitis eradication progress report. Annual report, $\mathrm{MOH}$ IRAQ-WHO, 2005.

10. World Health Organization, Ministry of health in Iraq. Acute flaccid paralysis surveillance. Field manual, $\mathrm{MOH}$ IraqWHO 2006.

11. Greenberg RS, Elay JW, Daniels SR, Boring JR. Medical epidemiology, Lange Medical Books, $3^{\text {rd }}$ ed., 2000.

12. Philip D., Lisam., Peter C., Mark H. Essential of family Medicine. $3^{\text {rd }}$ ed. New York, AAFP. 2002.

13. Al-Neami M A. Evaluation of disease surveillance system in Mosul city .Ph.D. thesis, University of Mosul, 2005. 